\title{
Prevalence of Diabetic Foot Ulcer and Associated Factors among Adult Diabetic Patients on Follow-Up Clinic at Jimma Medical Center, Southwest Ethiopia, 2019: An Institutional-Based Cross-Sectional Study
}

\author{
Daba Abdissa $\mathbb{D}^{1},{ }^{1}$ Tesfaye Adugna $\mathbb{D}^{2},{ }^{2}$ Urge Gerema $\mathbb{D}^{1},{ }^{1}$ and Diriba Dereje $\mathbb{D}^{3}$ \\ ${ }^{1}$ Department of Biomedical Sciences (Clinical Anatomy), College of Medical, Sciences, Institute of Health Sciences, \\ Jimma University, Ethiopia \\ ${ }^{2}$ Department of Biomedical Sciences (Medical Biochemistry), College of Medical, Sciences, Institute of Health Sciences, \\ Jimma University, Ethiopia \\ ${ }^{3}$ Department of Biomedical Sciences (Medical Physiology), College of Medical, Sciences, Institute of Health Sciences, \\ Jimma University, Ethiopia
}

Correspondence should be addressed to Daba Abdissa; dhaabaa4@gmail.com

Received 27 December 2019; Accepted 3 March 2020; Published 16 March 2020

Academic Editor: Munmun Chattopadhyay

Copyright (C) 2020 Daba Abdissa et al. This is an open access article distributed under the Creative Commons Attribution License, which permits unrestricted use, distribution, and reproduction in any medium, provided the original work is properly cited.

\begin{abstract}
Background. Diabetic foot ulceration is a devastating complication of diabetes mellitus and is a major source of morbidity and mortality. So far, there are few published data on diabetic foot ulcers and its determinants among diabetic patients on follow-up at Jimma Medical Center. Hence, the aim of this study was to assess the prevalence of diabetic foot ulcer and its determinants among patients with diabetes mellitus at Jimma Medical Center. Methods. A hospital-based cross-sectional study was conducted from June 1 to August 30,2019, and systematic random sampling technique was applied. The total number of study subjects who participated in the study was 277. Data were collected using an interview-administered structured questionnaire. Data were entered into EpiData version 3.1 and exported to SPSS version 20 software for analysis. Analysis was done using descriptive statistics and logistic regression. A variable having a $p$ value of $<0.25$ in the bivariate model was subjected to multivariate analysis to avoid confounding the variable's effect. Adjusted odds ratios (AOR) were calculated at 95\% confidence interval and considered significant with a $p$ value of $\leq 0.05$. Result. The mean of age of participants was $50.1 \pm 14.19$ years. More than threefourths of participants $(82.7 \%)$ were type $2 \mathrm{DM}$. The mean duration of diabetic patients was $6.00 \pm 5.07$ years. The prevalence of diabetic foot ulcer was $11.6 \%$ among study participants. According to multivariate logistic regression analysis, previous history of ulceration $(\mathrm{AOR}=5.77 ; 95 \% \mathrm{CI}: 2.37,14.0)$ and peripheral neuropathy ( $\mathrm{AOR}=11.2 ; 95 \% \mathrm{CI}: 2.8,44.4)$ were independent predictors of diabetic foot ulcer. Conclusion. The prevalence of diabetic foot ulcer was $11.6 \%$. Previous history of ulceration and peripheral neuropathy were associated with diabetic foot ulcer. The health care providers are recommended to thoroughly give emphasis during follow-up of patients who had previous history of ulceration and peripheral neuropathy in order to decrease the occurrence of diabetic foot ulcer.
\end{abstract}

\section{Introduction}

Diabetes has reached epidemic proportions worldwide. The International Diabetes Federation (IDF) estimates 425 million people living with DM worldwide in 2017, estimated to rise to 628 million by 2045. Sub-Saharan Africa is currently enduring the heaviest global burden of diabetes $[1,2]$.
Diabetic foot disease (DFD) is one of the diabetic complications associated with major morbidity, mortality, and reduced quality of life and is the most serious complication of diabetes mellitus $[3,4]$. The incidence of DFD is still rising [5]. According to the international consensus on diabetic foot, a foot ulcer is defined as a full-thickness wound below the ankle in a diabetic patient, irrespective of duration [6]. 
The International Diabetes Federation estimates that at least one limb is lost due to DFU somewhere in the world every 30 seconds [7]. DFU is the most common cause of hospitalization in diabetic patients and also has significant socioeconomic impact $[8,9]$. It is estimated that a person with diabetes has a $25 \%$ lifetime risk of developing DFU [10]. Patients with DFU have a greater than twofold increase in mortality compared with nonulcerated diabetic patients [11]. Five-year mortality rates after ulceration were around $40 \%$ [3]. Furthermore, the DFD and its long-term sequelae account for direct medical expenditures and lengthy periods of disability [12] .

According to a systematic review in 2017, the prevalence of foot ulcers among diabetic patients ranges from $3 \%$ to $13 \%$ globally [13]. In Africa, with constrained resources, the prevalence of DFU is higher. In sub-Saharan Africa, the burden of DFU is increasing due to late diagnosis, poor awareness among patients, and poor access to health care $[13,14]$.

DFU is preventable, and frequency of lower limb amputations can be lowered by $49-87 \%$ by preventing the development of DFU. Evidence in the literature suggests that the early detection and treatment of diabetic foot complications could reduce the prevalence of ulceration by $44 \%$ to $85 \%$ $[15,16]$. Increased age, male gender, peripheral vascular disease, peripheral neuropathy, and renal disease were common risk factors for death after ulceration [3]. Patients at risk of developing DFU can easily be identified by clinical examination of the feet during follow-up [17]. Early screening of high-risk patients is important to prevent development of foot ulcers and its associated morbidity. To date, data regarding prevalence and factors related to foot ulcers among diabetic patients in Jimma are relatively few, and point prevalence varies in previous studies. So, the aim of this study is to solve this gap.

\section{Methods}

2.1. Study Area and Period. This study was conducted in Jimma Medical Center (JMC) which is located in Jimma town, Jimma zone, $355 \mathrm{~km}$ to the southwest of Addis Ababa, the capital city of Ethiopia. JMC is one of the largest hospitals in our country serving a very large catchment area in the Southwestern Oromia region. It gives different specialized clinical services including chronic follow-up for diabetes mellitus, hypertension, and other chronic illnesses. The study was conducted from June 1 to August 30, 2019.

2.2. Study Design. An institution-based cross-sectional study was conducted among adult diabetic patients on the followup clinic at Jimma Medical Center.

2.3. Population. The source population includes all adult diabetic patients on the follow-up clinic at JMC, while the study population was all adult diabetic patients who were under routine follow-up at the JMC during the study period.

2.4. Eligibility Criteria. Participants of age $\geq 18$ years were included, and those who were seriously ill, gestational diabetic, diabetic patients who had traumatic ulcer, and clinically suspected of having Charcot foot were excluded.
2.5. Operational Definition. Diabetic foot ulcer: these are nontraumatic lesions of the skin on the foot distal to malleoli of a person who has diabetes mellitus.

Clinically suspected patient with Charcot foot: patients having DM for a long period of time and presented with a low level of sensation, swelling, and foot associated with midfoot collapse.

Peripheral neuropathy: this is defined as a patient with history version of MNSI questionnaire score $\geq 7$, abnormal responses in the legs and/or if the lower extremity examination version of MNSI scores $\geq 2.5$ in the legs [18].

Foot deformities: these are the presence of any of the following structural abnormalities in one or both feet: hammer toes, claw-toes, hallux valgus, prominent metatarsal heads, and amputations.

2.6. Sample Size Calculation and Sampling Procedure. The sample size was calculated using single population proportion formula by considering the prevalence of diabetic foot ulcer in Gondar, Ethiopia at $13.6 \%$ [19] at 95\% confidence level and a $4 \%$ margin of error. It gives an initial sample size of 280. Since the source population of diabetic patients at the JMC clinic is less than 10,000 , about 2500 , by using the population correction formula for a finite population, the final sample size was calculated to be 251 . By taking into consideration a $10 \%$ nonresponse rate, the final sample size was 277 .

A systematic random sampling technique was employed to select study participants. The diabetes clinic runs twice weekly, and there were about 2500 diabetic patients on follow-up taken from the diabetes mellitus outpatient unit manager. These patients were our sampling frame, and the patients included in the sample were selected at every ninth interval. We got the interval by dividing the source population (2500) to the final sample size (277) and obtained nine. The first patient was selected randomly from the first ninth by a lottery method, and the next patient was interviewed and examined every ninth interval until the required sample was attained.

2.7. Data Collection Tool. Data were collected through a validated, pretested, and structured questionnaire which was developed after reviewing different literatures. The questionnaire contains sociodemographic factors, behavioral variables, clinical variables, and anthropometric measurements.

Clinical variables were taken from the patient record review, and anthropometric measurements were measured. Body weight was measured while wearing light clothes by an adjusted weight scale. Height was measured by meter, standing upright on a flat surface. Behavioral variables were assessed based on the WHO STEPwise approach for chronic disease risk factor surveillance [20]. BMI was calculated as $\mathrm{kg} / \mathrm{m}^{2}$ to determine the nutritional status of the participant. Data collection was carried out by 2 BSC nurses and one medical intern with supervision of the principal investigator. After overnight fasting, blood samples were obtained for laboratory evaluation. The Michigan Neuropathy Screening Instrument was used to evaluate the presence of diabetic peripheral neuropathy (DPN) [21]. 
TABLE 1: Sociodemographic characteristics of patients with diabetes mellitus at JMC 2019, Jimma, Ethiopia.

\begin{tabular}{|c|c|c|c|}
\hline Variables & Category & Number & Percentage \\
\hline \multirow{2}{*}{ Sex } & Male & 165 & 59.6 \\
\hline & Female & 112 & 40.4 \\
\hline \multirow{4}{*}{ Age (in years) } & $<30$ & 32 & 11.6 \\
\hline & 30 to 39 & 24 & 8.7 \\
\hline & 40 to 49 & 72 & 26 \\
\hline & $\geq 50$ & 149 & 53.8 \\
\hline \multirow{3}{*}{ Marital status } & Married & 224 & 80.9 \\
\hline & Single & 44 & 15.9 \\
\hline & Others* & 9 & 3.2 \\
\hline \multirow{4}{*}{ Education status } & Illiterate & 86 & 31 \\
\hline & Primary & 119 & 43 \\
\hline & Secondary & 34 & 12.3 \\
\hline & College and above & 38 & 13.7 \\
\hline \multirow{5}{*}{ Occupational status } & Housewife & 84 & 30.3 \\
\hline & Farmer & 87 & 31.4 \\
\hline & Employer & 56 & 20.2 \\
\hline & Private worker & 36 & 13 \\
\hline & Others $^{\dagger}$ & 14 & 5.1 \\
\hline \multirow{2}{*}{ Residence } & Urban & 86 & 31 \\
\hline & Rural & 191 & 69 \\
\hline \multirow{4}{*}{$\begin{array}{l}\text { Income } \\
\text { (Ethiopian birr) }\end{array}$} & $<1000$ & 83 & 30 \\
\hline & 1000 to 1999 & 33 & 11.9 \\
\hline & 2000 to 2999 & 64 & 23.1 \\
\hline & $\geq 3000$ & 97 & 35 \\
\hline
\end{tabular}

${ }^{*}$ Widowed and divorced; ${ }^{\dagger}$ retired and unemployed.

2.8. Data Analysis. The collected data were checked for completeness and coded. Then, the data were entered into EpiData version 3.1 and then exported to SPSS version 20.0 for analysis. Descriptive statistics such as frequencies, percentages, means, and standard deviations were computed as necessary. Bivariate and multivariate logistic regression models were used to determine the degree of association between the outcome and predictor variables. Variables having a $p$ value of $<0.25$ in the bivariate model were subjected to multivariate analysis to avoid confounding the variables' effect. The goodness of fit of the multivariate model was checked with the Hosmer and Lemeshow test $(p=0.32)$. $p$ value $\leq$ 0.05 was taken as statistically significant.

2.9. Data Quality Assurance. Data quality was ensured through standardized data collection materials, and questionnaires were thoroughly checked for completeness and consistency. To ensure the quality of data and cultural acceptance of the tool, pretests of data collection tools were carried out on 14 diabetes patients attending the Shenen Gibe hospital diabetic clinic prior to actual data collection. After analyzing pretest results, necessary modifications and corrections were made. Every day, the collected data was checked for
TABLE 2: Clinical and behavioral characteristics of patients with diabetes mellitus at JMC 2019, Jimma, Ethiopia.

\begin{tabular}{|c|c|c|c|}
\hline Variables & Category & Number & Percentage \\
\hline \multirow{2}{*}{ Type of DM } & 1 & 48 & 17.3 \\
\hline & 2 & 229 & 82.7 \\
\hline \multirow{3}{*}{ Duration of DM } & $<5$ years & 156 & 56.3 \\
\hline & 5 to 10 years & 73 & 26.4 \\
\hline & $\geq 10$ years & 48 & 17.3 \\
\hline \multirow{4}{*}{ BMI } & $<18.5$ & 29 & 10.5 \\
\hline & 18.5 to 24.9 & 189 & 68.2 \\
\hline & 25-29.9 & 44 & 15.9 \\
\hline & $\geq 30$ & 15 & 5.4 \\
\hline \multirow{3}{*}{ Alcohol intake } & Current & 33 & 11.9 \\
\hline & Former & 25 & 89 \\
\hline & Never & 219 & 79.1 \\
\hline \multirow{3}{*}{ Smoking } & Current & 14 & 5.1 \\
\hline & Former & 41 & 14.8 \\
\hline & Never & 222 & 80.1 \\
\hline \multirow{2}{*}{ Physical exercise } & Active & 115 & 41.5 \\
\hline & Inactive & 162 & 58.5 \\
\hline \multirow{2}{*}{ Comorbid hypertension } & Yes & 86 & 31 \\
\hline & No & 191 & 69 \\
\hline \multirow{2}{*}{ Fasting blood sugar } & $<200 \mathrm{mg} / \mathrm{dl}$ & 204 & 26.4 \\
\hline & $\geq 200 \mathrm{mg} / \mathrm{dl}$ & 73 & 73.6 \\
\hline \multirow{2}{*}{ History of ulceration } & Yes & 90 & 32.5 \\
\hline & No & 187 & 67.5 \\
\hline \multirow{2}{*}{ Peripheral neuropathy } & Yes & 129 & 46.6 \\
\hline & No & 148 & 53.4 \\
\hline \multirow{2}{*}{ Foot deformity } & Yes & 97 & 35 \\
\hline & No & 180 & 65 \\
\hline
\end{tabular}

completeness. Consequently, amendments and corrections were made.

2.10. Ethical Consideration. Ethical clearance was obtained from the Jimma University Institutional Review Board. A supportive formal letter was written to Jimma Medical Center. Data collection was done after permissions were obtained from hospital managers, and oral informed consent was obtained from the study participants to start data collection.

\section{Result}

3.1. Sociodemographic Characteristics of Participants. A total of two hundred and seventy-seven participants were involved in this study. More than half (165) of the respondents were males and the rest (112) were females. The mean age of the respondents was $50.1 \pm 14.28$ years. Regarding the marital status of the respondents, more than three-fourths $(224,80.9 \%)$ were married followed by singles $(44,15.9 \%)$ (Table 1). 
TABLE 3: Independent predictors of diabetic foot ulcer among diabetic patients at JMC 2019, Jimma, Ethiopia.

\begin{tabular}{|c|c|c|c|c|c|c|c|}
\hline \multirow{2}{*}{ Variables } & \multirow{2}{*}{ Category } & \multicolumn{2}{|c|}{ Diabetic foot ulcer } & \multicolumn{2}{|c|}{ Bivariate analysis } & \multicolumn{2}{|c|}{ Multivariate analysis } \\
\hline & & Yes & No & $p$ value & COR (95\% CI) & $p$ value & $\operatorname{AOR}(95 \% \mathrm{CI})$ \\
\hline \multirow{4}{*}{ Age } & $<30$ & 1 & 31 & 1 & 1 & 1 & 1 \\
\hline & $30-39$ & 2 & 22 & 0.409 & $2.8(0.24,33.04)$ & $* *$ & \\
\hline & $40-49$ & 9 & 63 & 0.167 & $4.4(0.54,36.5)$ & $* *$ & \\
\hline & $\geq 50$ & 29 & 129 & 0.133 & $4.8(0.62,37.2)$ & & \\
\hline \multirow{3}{*}{ Smoking } & Current & 8 & 23 & 0.023 & $2.91(1.15,7.33)$ & $* *$ & \\
\hline & Former & 3 & 46 & 0.345 & $\begin{array}{c}0.547(0.156 \\
1.91)\end{array}$ & $* *$ & \\
\hline & Never & 21 & 176 & 1 & 1 & 1 & 1 \\
\hline \multirow{2}{*}{ Physical exercise } & Active & 10 & 105 & 1 & 1 & 1 & 1 \\
\hline & Inactive & 22 & 140 & 0.21 & $1.65(0.75,3.63)$ & $* *$ & \\
\hline \multirow{2}{*}{$\begin{array}{l}\text { Peripheral } \\
\text { neuropathy }\end{array}$} & Yes & 27 & 95 & 0.00 & $8.53(3.17,22.9)$ & $0.001^{*}$ & $11.2(2.8,44.4)$ \\
\hline & No & 5 & 150 & 1 & 1 & 1 & 1 \\
\hline \multirow{2}{*}{ History of ulceration } & Yes & 23 & 67 & 0.00 & $6.78(2.99,15.41)$ & $0.00^{*}$ & $5.77(2.37,14.0)$ \\
\hline & No & 9 & 178 & 1 & 1 & 1 & 1 \\
\hline \multirow{3}{*}{ Alcohol intake } & Current & 1 & 32 & 0.136 & $0.21(0.028,1.62)$ & $* *$ & \\
\hline & Ex-drinker & 3 & 22 & 0.911 & $0.93(0.26,3.31)$ & & \\
\hline & Never & 28 & 191 & 1 & 1 & 1 & 1 \\
\hline \multirow{2}{*}{ Type of DM } & T1DM & 3 & 45 & 0.216 & $0.46(0.13,1.57)$ & $* *$ & \\
\hline & $\mathrm{T} 2 \mathrm{DM}$ & 29 & 200 & 1 & 1 & & \\
\hline \multirow{2}{*}{ Foot deformity } & No & 14 & 166 & 1 & 1 & 1 & 1 \\
\hline & Yes & 18 & 79 & 0.009 & $0.37(0.175,782)$ & $* *$ & \\
\hline
\end{tabular}

*Value statistically significant. AOR: adjusted odds ratio; COR: crude odds ratio; CI: confidence interval 1-reference. ${ }^{* *}$ Not statistically associated with diabetic foot ulcer.

\subsection{Clinical and Behavioral Characteristics of Participants.} Greater than three-fourths $(82.7 \%)$ of the participants were type 2 DM. More than half (56.3\%) of them were diagnosed with diabetes for less than 5 years, and almost one-third (31\%) had no comorbid hypertension. A total of 189 $(68.2 \%)$ of the study participants were in the normal category of BMI, whereas $44(15.9 \%)$ of the participants were overweight. One hundred twenty-nine (46.6\%) had diabetic peripheral neuropathy (Table 2).

3.3. Factors Independently Associated with Diabetic Foot Ulcer. Diabetic patients who had peripheral neuropathy were 11.2 times more likely to develop diabetic foot ulcer as compared with those who had no peripheral neuropathy (AOR $=11.2 ; 95 \%$ CI 2.8, 44.4; $p=0.001)$. Likewise, diabetic patients who had a history of ulceration were 5.77 times more likely to develop diabetic foot ulcer as compared with those who had no history of ulceration ( $p$ value $=0.00$; AOR $=$ 5.77 ; $95 \%$ CI $2.37,14.0)$ provided other factors remain the same (Table 3 ).

\section{Discussion}

In the present study, the prevalence of diabetic foot ulcers among diabetic patients attending JMC was 11.6\% (95\%
CI: $7.9,15.5)$. This finding is in line with three independent studies done in Ethiopia, 13.6\% in Gondar, 12\% in Mekelle, and $14.8 \%$ in Arbaminch $[19,22,23]$. In addition, similar finding in North India (14.3\%) and in Tanzania (15\%) $[24,25]$. However, this finding was lower than the study done in Addis Ababa, Ethiopia (31.1\%) [26]; Telangana, India (16\%) [27]; and Jordan (4.6\%) [28]. The possible reason for such discrepancy might be due to difference in sample size used, study design, knowledge about foot selfcare, health-seeking behavior, and health infrastructure of study participants.

In contrast, the finding of the current study is higher than a study conducted in Kenya which reported 4.6\% [29]; Wollo, Ethiopia (4.4\%) [30]; and Ghana which was $3.8 \%$ [31]. The possible difference might be due to difference in sample size, study design, and eligibility criteria.

The current finding demonstrated that participants who had peripheral neuropathy were 11.2 times more likely to develop diabetic foot ulcer than diabetic patients without peripheral neuropathy $(\mathrm{AOR}=11.2 ; 95 \% \mathrm{CI}: 2.8$, 44.4). This result is consistent with prior studies [19, 27].This association is possibly because DPN promotes ulcer formation by causing loss of protective pain sensation, loss of pressure perception, and impairment of microcirculation $[32,33]$. 
Furthermore, according to the current finding, participants who had a history of foot ulceration were 5.77 times more likely to develop diabetic foot ulcer than those without a previous history of foot ulceration $(\mathrm{AOR}=5.77 ; 95 \% \mathrm{CI}$ : $2.37,14)$. The result is consistent with prior studies in Ghana and England [31,34]. This association can be explained by biomechanical factors such as the degree of barefoot and in-shoe mechanical stress and the level of adherence to wearing prescribed footwear. In addition, it may be due to the fact that ulcer leads to microvascular dysfunction, macrovascular dysfunction, and peripheral nerve damage [35].

\section{Conclusion}

The prevalence of diabetic foot ulcer was $11.6 \%$ among study participants. Previous history of ulceration and peripheral neuropathy were independent predictors of diabetic foot ulcer. The health care providers are recommended to give emphasis during follow-up of patients who had a previous history of ulceration and manage the neuropathy thoroughly in order to decrease the occurrence of diabetic foot ulcer. In addition, future efforts should be directed toward educating both the healthcare professionals and patients about proper foot care.

5.1. Limitation of the Study. The duration of diabetes as measured in this study might not reflect the true duration of the disease, because the time since diagnosis and actual diabetes onset might precede diagnosis type 2 diabetes. Another limitation is the cross-sectional nature of the study which does not confirm the definitive cause and effect relation.

We did not asses the vascular status of our study population, so that we could not asses the prevalence of peripheral arterial disease.

\section{Abbreviations}

AOR: Adjusted odds ratio

BMI: Body mass index

CI: Confidence interval

DM: Diabetes mellitus

DFD: Diabetic foot disease

DFU: Diabetic foot ulcer

COR: Crude odds ratio

JMC: Jimma Medical Center.

\section{Data Availability}

The original data of this study could be available for the third body only up on authors request.

\section{Conflicts of Interest}

The authors of this study declare that they have no competing interests.

\section{Authors' Contributions}

DA conceived the idea, wrote the proposal, analyzed the data, and drafted the paper.UG participated by revising and approving the proposal. DD wrote the proposal, participated in data collection, analyzed the data, and drafted the paper. DA and TA participated by revising and approving the proposal, participated in the data analysis, and revised subsequent drafts of the paper. All authors read and approved the final manuscript data analysis and revised subsequent drafts of the paper.

\section{Acknowledgments}

First of all, I would like to praise my God; without his help, all this would have been impossible. Also, I want to acknowledge my data collectors, colleagues, and study participants. Lastly, I would like to thank Jimma University Medical Center for providing relevant information.

\section{References}

[1] N. Cho, J. E. Shaw, S. Karuranga et al., "IDF Diabetes Atlas: global estimates of diabetes prevalence for 2017 and projections for 2045," Diabetes Research and Clinical Practice, vol. 138, pp. 271-281, 2018.

[2] A. Elbarsha, M. A. I. Hamedh, and M. Elsaeiti, "Prevalence and risk factors of diabetic peripheral neuropathy in patients with type 2 diabetes mellitus," Ibnosina Journal of Medicine and Biomedical Sciences, vol. 11, no. 1, p. 25, 2019.

[3] D. C. Jupiter, J. C. Thorud, C. J. Buckley, and N. Shibuya, "The impact of foot ulceration and amputation on mortality in diabetic patients. I: from ulceration to death, a systematic review," International Wound Journal, vol. 13, no. 5, pp. 892-903, 2016.

[4] N. C. Schaper, J. J. van Netten, J. Apelqvist, B. A. Lipsky, K. Bakker, and on behalf of the International Working Group on the Diabetic Foot (IWGDF), "Prevention and management of foot problems in diabetes: a summary guidance for daily practice 2015, based on the IWGDF guidance documents," Diabetes/Metabolism Research and Reviews, vol. 32, pp. 7-15, 2016.

[5] N. Amin and J. Doupis, "Diabetic foot disease: from the evaluation of the "foot at risk" to the novel diabetic ulcer treatment modalities," World Journal of Diabetes, vol. 7, no. 7, pp. 153164, 2016.

[6] J. Apelqvist, K. Bakker, W. H. van Houtum, M. H. NabuursFranssen, N. C. Schaper, and on behalf of the International Working Group on the Diabetic Foot, "International consensus and practical guidelines on the management and the prevention of the diabetic foot," Diabetes/Metabolism Research and Reviews, vol. 16, no. S1, pp. S84-S92, 2000.

[7] I. D. Federation, IDF Diabetes Atlas 8th Edition (2017), 2017.

[8] M. Volmer-Thole and R. Lobmann, "Neuropathy and diabetic foot syndrome," International Journal of Molecular Sciences, vol. 17, no. 6, p. 917, 2016.

[9] Y. Khan, M. M. Khan, and M. Raza Farooqui, "Diabetic foot ulcers: a review of current management," International Journal of Research in Medical Sciences, vol. 5, no. 11, pp. 4683-4689, 2017.

[10] N. Singh, D. G. Armstrong, and B. A. Lipsky, "Preventing foot ulcers in patients with diabetes," Journal of the American Medical Association, vol. 293, no. 2, pp. 217-228, 2005. 
[11] N. K. Chammas, R. L. R. Hill, and M. E. Edmonds, "Increased mortality in diabetic foot ulcer patients: the significance of ulcer type," Journal Diabetes Research, vol. 2016, pp. 1-7, 2016.

[12] D. E. Bild, J. V. Selby, P. Sinnock, W. S. Browner, P. Braveman, and J. A. Showstack, "Lower-extremity amputation in people with diabetes: epidemiology and prevention," Diabetes Care, vol. 12, no. 1, pp. 24-31, 1989.

[13] P. Zhang, J. Lu, Y. Jing, S. Tang, D. Zhu, and Y. Bi, "Global epidemiology of diabetic foot ulceration: a systematic review and meta-analysis," Annals of Medicine, vol. 49, no. 2, pp. 106-116, 2016.

[14] N. S. Levitt, "Diabetes in Africa: epidemiology, management and healthcare challenges," Heart, vol. 94, no. 11, pp. 13761382, 2008.

[15] Federation ID, "IDF diabetes atlas," Bruss Belg Int Diabetes Fed. 2015, 2013.

[16] P. Holstein, N. Ellitsgaard, B. Bornefeldt Olsen, and V. Ellitsgaard, "Decreasing incidence of major amputations in people with diabetes," Diabetologia, vol. 43, no. 7, pp. 844-847, 2000.

[17] M. Zubair, A. Malik, and J. Ahmad, "Diabetic foot ulcer: a review," American Journal of Internal Medicine, vol. 3, no. 2, pp. 28-49, 2015.

[18] E. L. Feldman, M. J. Stevens, P. K. Thomas, M. B. Brown, N. Canal, and D. A. Greene, "A practical two-step quantitative clinical and electrophysiological assessment for the diagnosis and staging of diabetic neuropathy," Diabetes Care, vol. 17, no. 11, pp. 1281-1289, 1994.

[19] T. G. Mariam, A. Alemayehu, E. Tesfaye et al., "Prevalence of Diabetic Foot Ulcer and Associated Factors among Adult Diabetic Patients Who Attend the Diabetic Follow-Up Clinic at the University of Gondar Referral Hospital, North West Ethiopia, 2016: Institutional-Based Cross- Sectional Study," Journal Diabetes Research, vol. 2017, article 2879249, 8 pages, 2017.

[20] L. Riley, R. Guthold, M. Cowan et al., "The World Health Organization STEPwise approach to non-communicable disease risk-factor surveillance: methods, challenges, and opportunities," American Journal of Public Health, vol. 106, no. 1, pp. 74-78, 2016.

[21] W. H. Herman, R. Pop-Busui, B. H. Braffett et al., "Use of the Michigan Neuropathy Screening Instrument as a measure of distal symmetrical peripheral neuropathy in type 1 diabetes: results from the Diabetes Control and Complications Trial/Epidemiology of Diabetes Interventions and Complications," Diabetic Medicine, vol. 29, no. 7, pp. 937-944, 2012.

[22] K. Gebrekirstos, S. Gebrekiros, and A. Fantahun, "Prevalence and factors associated with diabetic foot ulcer among adult patients in Ayder referral hospital diabetic clinic Mekelle, North Ethiopia, 2013," Journal of Diabetes \& Metabolism, vol. 6, no. 8, p. 2, 2015.

[23] B. Deribe, K. Woldemichael, and G. Nemera, "Prevalence and factors influencing diabetic foot ulcer among diabetic patients attending Arbaminch Hospital, South Ethiopia," Journal of Diabetes \& Metabolism, vol. 5, no. 1, pp. 1-7, 2014.

[24] F. S. Chiwanga, Diabetic foot: prevalence, risk factors, knowledge and practices of foot care among diabetic patients attending public diabetic clinics in Dar-es-salaam, Tanzania [PhD thesis], Muhimbili University of Health and Allied Sciences, 2008.

[25] S. K. Shahi, A. Kumar, S. Kumar, S. K. Singh, S. K. Gupta, and T. B. Singh, "Prevalence of diabetic foot ulcer and associated risk factors in diabetic patients from North India," The Journal of Diabetic Foot Complications, vol. 4, no. 3, pp. 83-91, 2012.

[26] W. Amogne, A. Reja, and A. Amare, "Diabetic foot disease in Ethiopian patients: a hospital based study," Ethiopian Journal of Health Development, vol. 25, no. 1, pp. 17-21, 2011.

[27] S. M. Kantva and M. Kumar, "Risk factors of diabetic foot ulcer at a tertiary care hospital among diabetic patients," International Journal of Medical and Biomedical Studies, vol. 3, no. 8, 2019.

[28] F. G. Bakri, A. H. Allan, Y. S. Khader, N. A. Younes, and K. M. Ajlouni, "Prevalence of diabetic foot ulcer and its associated risk factors among diabetic patients in Jordan," Jordan Medical Journal, vol. 171, no. 785, pp. 1-16, 2012.

[29] P. N. Nyamu, C. F. Otieno, E. O. Amayo, and S. O. McLigeyo, "Risk factors and prevalence of diabetic foot ulcers at Kenyatta National Hospital, Nairobi," East African Medical Journal, vol. 80, no. 1, pp. 36-43, 2003.

[30] A. A. Abejew, A. Z. Belay, and M. W. Kerie, "Diabetic complications among adult diabetic patients of a tertiary hospital in northeast Ethiopia," Advances in Public Health, vol. 2015, Article ID 290920, 7 pages, 2015.

[31] I. Amissah and M. Amoako-Boateng, "Prevalence of diabetes mellitus complications among people with type 2 diabetes mellitus attending a teaching hospital in Ghana: a clinical audit," International Journal of Science and Research, vol. 3, no. 11, pp. 2104-2109, 2014.

[32] K. Alexiadou and J. Doupis, "Management of diabetic foot ulcers," Diabetes Therapy, vol. 3, no. 1, p. 4, 2012.

[33] P.-C. Sun, C.-D. Kuo, L.-Y. Chi, H.-D. Lin, S.-H. Wei, and C.-S. Chen, "Microcirculatory vasomotor changes are associated with severity of peripheral neuropathy in patients with type 2 diabetes," Diabetes \& Vascular Disease Research, vol. 10, no. 3, pp. 270-276, 2013.

[34] C. A. Abbott, A. L. Carrington, H. Ashe et al., "The NorthWest Diabetes Foot Care Study: incidence of, and risk factors for, new diabetic foot ulceration in a community-based patient cohort," Diabetic Medicine, vol. 19, no. 5, pp. 377-384, 2002.

[35] R. Waaijman, M. de Haart, M. L. J. Arts et al., "Risk factors for plantar foot ulcer recurrence in neuropathic diabetic patients," Diabetes Care, vol. 37, no. 6, pp. 1697-1705, 2014. 